\title{
Occurrences of Green Oyster and Heavy Metals Contaminant Levels in the Sien- San Area, Taiwan
}

\author{
SAULWOOD LIN* and I-JY HSIEH \\ Institute of Oceanography, National Taiwan University, Taipei, Taiwan, ROC
}

An abnormal increase of copper concentrations was observed in both the oyster tissues and sediments of the SienSan coastal area in the north-western part of Taiwan. As much as 200 and 5000 ppm of copper was found in sediments and oysters. These excessive concentrations of copper were introduced to the coastal area within a short period of about $4 \mathrm{yr}$. Copper concentrations increased 50 and 100-fold respectively in oyster tissues and sediments. The green oyster phenomenon occurred as a result of these rapid increases in metal concentrations. The appearance of green oysters and the abnormal concentrations of copper demonstrated that the Sien-San coastal area is undergoing a drastic change as a result of copper pollution. This pollution problem represents a serious threat to the local fishing community. (C) 1999 Elsevier Science Ltd. All rights reserved.

Keywords: heavy metals; green oysters; sediments; copper; Bay; Taiwan.

Toxic metals released into the marine environments tend to accumulate in sediments and subsequently are taken up by filter-feeding organisms. Marked variations in the bivalves heavy metal concentrations along the US coasts demonstrated that bivalves such as oysters and mussels are valuable biomonitoring tools for assessing the chemical pollution of the coastal environments (Lauenstein et al., 1990; Presley et al., 1990; Goldberg et al., 1983).

Oysters and other bivalves accumulate metals such as copper and zinc and can tolerate very high metal concentrations without apparent signs of any detrimental effect. Up to $1700 \mathrm{ppm}$ of $\mathrm{Cu}$ and $14000 \mathrm{ppm}$ of $\mathrm{Zn}$ were found in oysters from Tasmania (Ayling, 1974), and 1413 ppm of $\mathrm{Cu}$ and 8629 ppm of $\mathrm{Zn}$ from Hong Kong (Phillips et al., 1979). In the US Mussel Watch, the

*Corresponding author. Fax: + 886-2-362-6092 highest copper concentration (2100 ppm) was found in oysters from Honolulu Harbor, Hawaii, and zinc (13000 ppm) from Delaware Bay, Delaware (NOAA, 1989). Most studies indicated that elevations of contaminants in oysters and other bivalves were found in the marine ecosystems near heavily populated locations or locations receiving runoff from lands used for industrial or agricultural purposes.

The main purpose of this study is to assess the status of oyster and sediment heavy metal concentrations in the coastal region of Sien-San and the extensive changes occurring within a period of $4 \mathrm{yr}$. The study involved the collecting of oysters and sediment samples inside a semienclosed bay, analyses of the heavy metal concentrations and comparison of the results with those samples from 1993 in the same area. This paper describes the unusual heavy metal contaminant levels in oysters and sediments and the occurrences of green oysters in the Sien-San area.

\section{Materials and Methods}

\section{Site description}

Sien-San is a small city of about $55 \mathrm{~km}^{2}$ with a population of 58328 (1997) in north-western Taiwan. Oyster cultivation was a major source of income for the local community prior to recent developments. Its oyster production for 1996 was 53 tons (Fisheries Bureau, 1997). A blooming computer-related high-tech industrial park has been established in the vicinity. A municipal open-field coastal garbage dump and incinerator facility are located approximately $20 \mathrm{~km}$ north of the study area.

Oysters are cultivated along the central waterway of the semi-enclosed bay throughout the year for purpose of mariculture (Fig. 1, shaded area). The entire area (Fig. 1, white area) is flooded at high tide (1-2 m deep) and partially exposed to the air at low tide. The deepest 


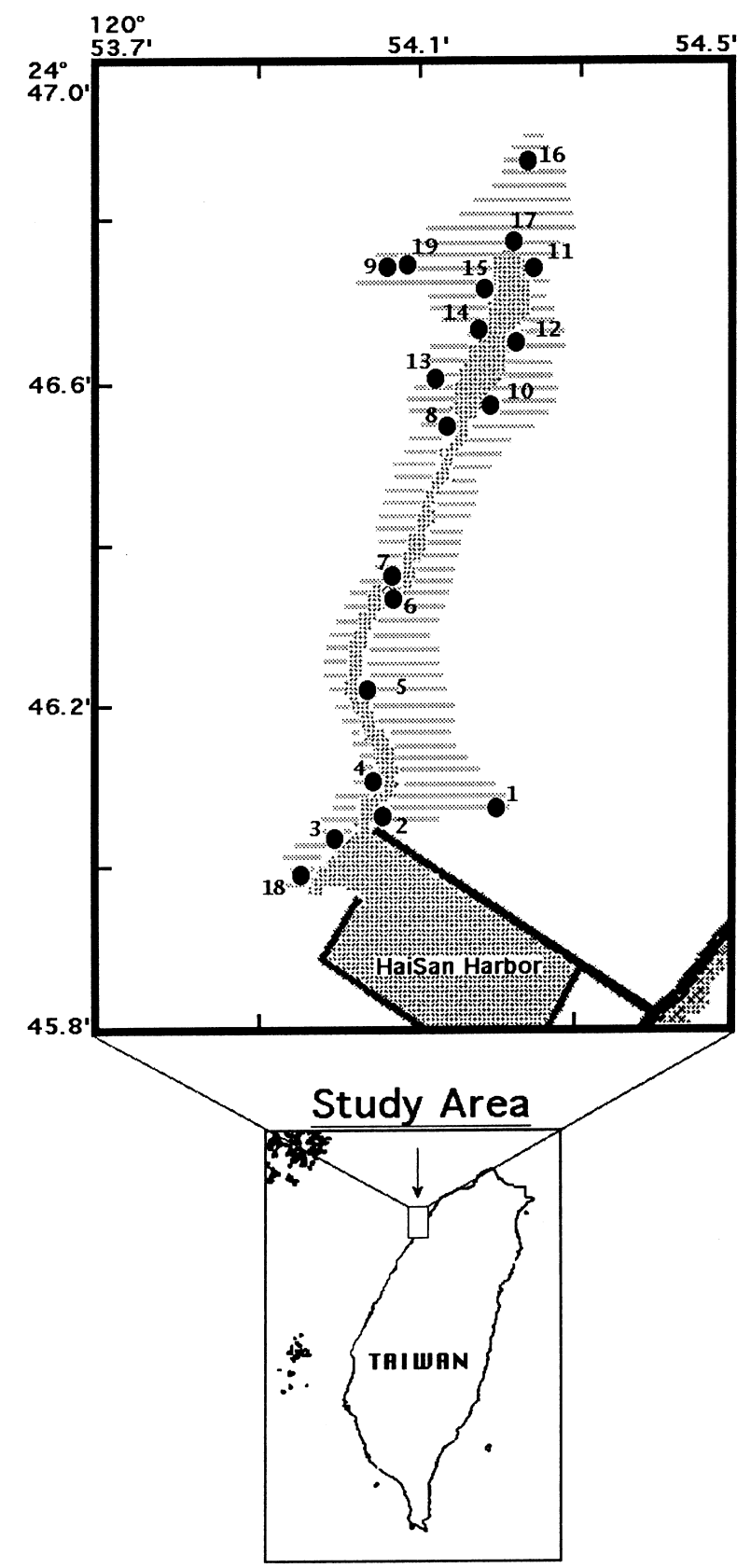

Fig. 1 Study area and sampling locations. The shaded area (horizontal lines) depicts the presently existing oyster racks.

area of the bay, about 5-6 m deep extending in a northeast/south-west direction, is used for a boat channel. At low tide, the south-west opening provides the only source of seawater.

\section{Sampling and analyses}

Oysters (Crassostrea gigas) and surface sediments were collected in 1993 and 1997 (Fig. 1). Oyster samples were collected directly above each sediment sample from the oyster farming racks. Sediments adhering to the oyster shell were washed thoroughly in the field. All samples were packed in an ice-chest at $4^{\circ} \mathrm{C}$ while being shipped back to the lab. Each individual oyster was shucked and washed with deionized water (Milli-Q, 18
$\Omega$ ), dried, weighted and stored frozen in a pre-cleaned glass bottle prior to digestion. Surface sediments were stored in polyethylene (PE) bottles at $4^{\circ} \mathrm{C}$ in the field and frozen in the lab until drying. Sediments were freeze-dried using a Labconco freeze-dryer (Lyph-Lock, 61 ) for one week, and ground to a fine powder using an Agate mortar and stored in PE vials.

Each oyster sample was individually digested with concentrated nitric acid (Merck, Tracerpur) in a water bath $\left(90^{\circ} \mathrm{C}\right)$ for $4 \mathrm{~h}$ in glass vials. The extractant was stored in acid-cleaned PE vials for metal analyses. Sediments $(\sim 0.25 \mathrm{~g})$ were digested in a Teflon lined digestion vessel using a CEM microwave (MDS-2000) based on Kokto et al. (1992). A mixed reagent (conc. $\mathrm{HNO}_{3} /$ HF: $5 / 2$ ) of $2.5 \mathrm{ml}$ was added to each vessel and heated with $100 \%$ power for $10 \mathrm{~min}$. At the second step, the microwave was set up at $75 \%$ power for $20 \mathrm{~min}$ and $25 \%$ power for $5 \mathrm{~min}$. After the pressure dropped to 1 atm, the digestion vessels were opened and $10 \mathrm{ml}$ of $4 \%$ $\mathrm{H}_{3} \mathrm{BO}_{3}$ was added and the above heating procedures were repeated. Upon completion of the digestion process, the digested solution was stored in PE vials for analyses. A NIST-1646a Standard Sediment and a CNRC DOLT-2 Standard Dogfish liver were used in each batch digestion for recovery test.

Heavy metals (Al, Fe, Mn, Zn: flame; $\mathrm{Cu}, \mathrm{Pb}, \mathrm{Cd}$ : graphite) were determined using a Hitachi $8100 \mathrm{Z}$ atomic absorption spectrometer. For metals high in concentrations, i.e., iron, manganese and zinc, the extracted solution was diluted (20-200 times) with deionized water and the concentrations were determined by calibration curves prepared from Merck Standard Metal Solution. For copper, lead and cadmium, the standard addition technique was employed in order to minimize the matrix effect. The accuracy of the metal analysis was determined by the total dissolution of the NIST-1646 Standard Sediment and CNRC DOLT-2 (Table 1). Relative errors, as compared to the Standards, were better than $6 \%$ for the measured metals.

\section{Results and Discussion}

\section{Green oyster}

The first sign of change in oyster colour was detected in June 1997. Initially, the tissue colour appeared in a very faint green colour with an average copper concentration of $478 \pm 175 \mathrm{ppm}$ (October, Table 2). The colour (Fig. 2) rapidly turned to a bright green within 5 months after the first sign of change was observed. Meanwhile, copper and zinc average concentrations progressively increased with time (Table 2). The average copper concentration reached $2074 \pm 742$ ppm dry weight $(n=95)$ for those samples collected between January and February 1998. The highest copper concentration of 4752 ppm was also found in the same period. Green oyster was a common phenomenon by February 1998. All 95 oyster specimens collected throughout the area showed signs of green colour with a lowest copper concentration 
TABLE 1

The analytical accuracy and precision of this study using the NIST Standard Sediment and CNRC DOLT-2 standard tissue.

\begin{tabular}{|c|c|c|c|c|}
\hline \multirow[t]{2}{*}{ Metal analysed } & \multicolumn{2}{|c|}{ NIST $1646 \mathrm{a}$} & \multicolumn{2}{|c|}{ DOLT-2 } \\
\hline & Certified & This study $(n=5)$ & Certified & This study $(n=10)$ \\
\hline $\mathrm{Fe}(\%)$ & $2.008 \pm 0.039$ & $1.98 \pm 0.10$ & - & - \\
\hline $\mathrm{Zn}(\mathrm{ppm})$ & $48.9 \pm 1.6$ & $47.5 \pm 0.65$ & $85.8 \pm 2.5$ & $81.0 \pm 3.1$ \\
\hline $\mathrm{Cu}(\mathrm{ppm})$ & $10.01 \pm 0.34$ & $9.99 \pm 0.45$ & $25.8 \pm 1.1$ & $25.2 \pm 1.6$ \\
\hline $\mathrm{Pb}(\mathrm{ppm})$ & $11.7 \pm 1.2$ & $11.3 \pm 0.95$ & $1.91 \pm 0.04$ & $1.80 \pm 0.02$ \\
\hline $\mathrm{Cd}(\mathrm{ppm})$ & $0.148 \pm 0.007$ & $0.164 \pm 0.02$ & $20.8 \pm 0.5$ & $20.4 \pm 1.4$ \\
\hline
\end{tabular}

TABLE 2

Monthly average and ranges of copper and zinc concentrations (ppm, dry weight) in whole soft parts of oysters from the Sien-San area.

\begin{tabular}{|c|c|c|c|c|c|}
\hline \multirow{2}{*}{$\begin{array}{l}\text { Sample time } \\
\text { (month/year) }\end{array}$} & \multirow[t]{2}{*}{ Sample numbers } & \multicolumn{2}{|c|}{$\mathrm{Cu}(\mathrm{ppm})$} & \multicolumn{2}{|c|}{ Zn (ppm) } \\
\hline & & Range & Mean $\pm 1 \sigma$ & Range & Mean $\pm 1 \sigma$ \\
\hline $10 / 1987$ & 80 & $221-993$ & $478 \pm 175$ & $536-2190$ & $1100 \pm 350$ \\
\hline $11 / 1987$ & 10 & $93.2-1080$ & $503 \pm 258$ & $170-2610$ & $1030 \pm 670$ \\
\hline $12 / 1987$ & 10 & $252-973$ & $679 \pm 242$ & $708-2120$ & $1330 \pm 486$ \\
\hline $1-2 / 1998$ & 95 & $506-4750$ & $2070 \pm 742$ & $877-5830$ & $2620 \pm 926$ \\
\hline
\end{tabular}

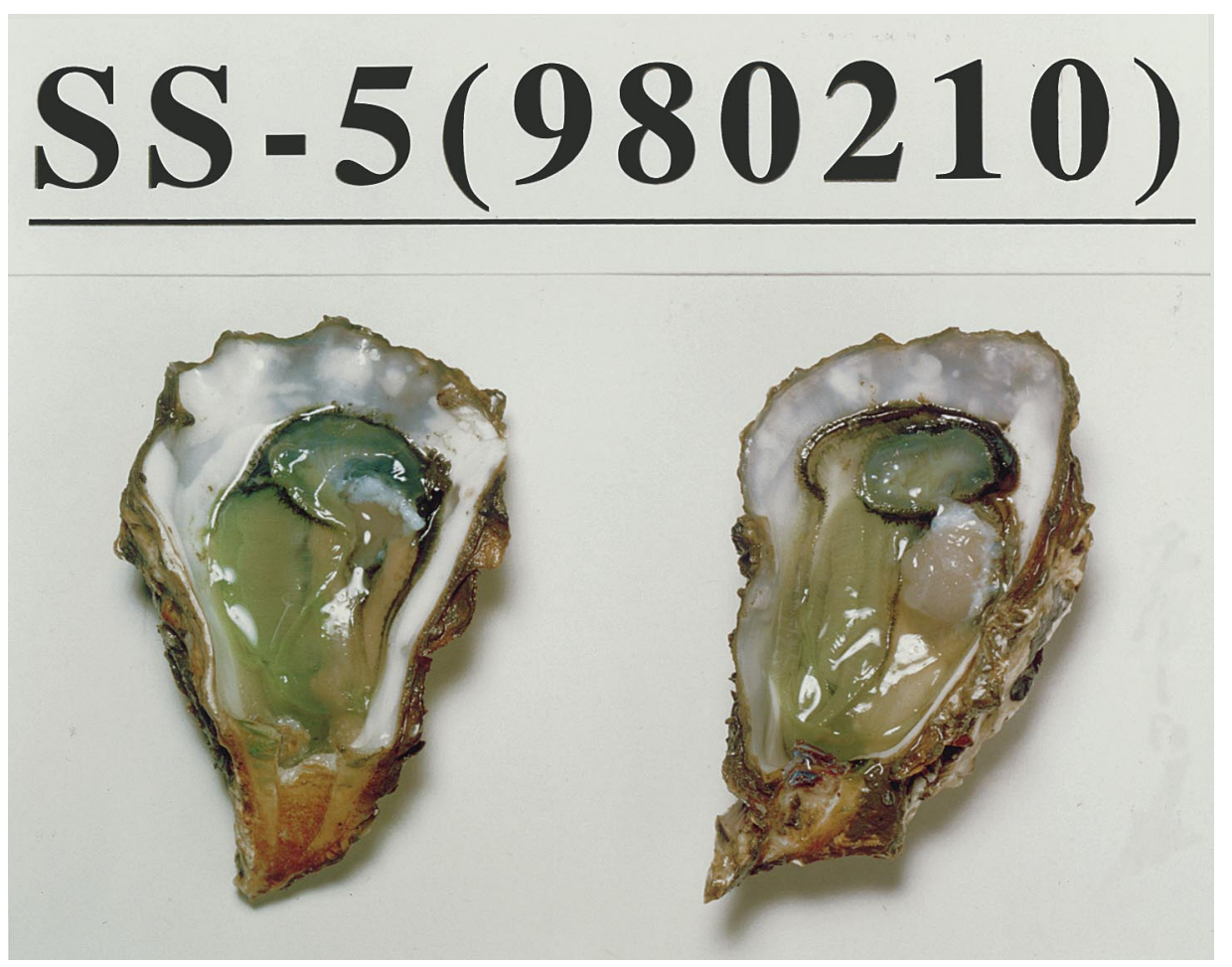

Fig. 2 Green oysters from the Sien-San area. The length of the shell measured diagonally is $7.3 \mathrm{~cm}$ (left) and $8.2 \mathrm{~cm}$ (right).

of $506 \mathrm{ppm}$. Zinc also showed a similar pattern with the highest concentration of $5829 \mathrm{ppm}$ found in the study area.

The high copper concentration observed in the SienSan area is one of the highest in the existing literature. In addition, very few reported a persistent presence of a high copper concentration on a scale similar to the SienSan area. Phillips et al. (1979) reported a rock oyster copper concentration of $1413 \mathrm{ppm}$ as an indication of metal discharge into Victoria Harbor, Hong Kong. Pridmore et al. (1990) reported a copper concentration of 1219 ppm for oysters from Manukau Harbor, New Zealand. With the exception of $2100 \mathrm{ppm}$ copper found in Honolulu Harbor, Hawaii (NOAA, 1989), very few oyster copper concentrations exceeded more than 500 ppm in the US from the Mussel Watch studies (Presley et al., 1990; O'Connor, 1996). The highest oyster copper concentration was $2722 \pm 98$ ppm reported by Han and 
Hung (1990) as a result of effluent pollution from the scrap metal reprocessing plants in south-west Taiwan.

The high copper concentrations found in the oysters grown in the study area clearly indicate that these oysters are undergoing a severe stress of copper pollution. The appearance of a green colour once oysters were exposed to an abnormally high concentration of copper was first noted as early as 1886 by Lankester (1886). The name "green-sick" oyster was used, and the green colour was attributed to the copper contained in the flesh. George et al. (1978) further showed that the colourization of the oyster flesh was the result of a self-detoxification effect from the copper pollutant. The oysters grown in the study area are evidently subject to the severe stress of copper pollution. Almost all oysters grown in the entire area showed high concentrations of copper with varying degrees of green colour.

\section{Rapid increase of metals}

The oyster metal contents in the 1997 sampling period were compared to those obtained from the same area in 1993 (Fig. 3). A drastic change in oyster $\mathrm{Cu}, \mathrm{Zn}, \mathrm{Pb} \mathrm{Cd}$ concentrations was found between the 1993 and 1997 samples. The metal concentrations in the 1993 oysters samples were within a narrow range $(\mathrm{Cu}: 40-200 \mathrm{ppm}$,
Zn: $110-470$ ppm, Pb: 0.11-0.98 ppm, Cd: 0.06-0.42 ppm) (Fig. 3), as compared with the drastic increase of metal concentrations of those observed in the 1997 samples. Copper concentrations increased to 200-5000 ppm, an increase of 5-50 times, and zinc 890-6000 ppm, representing an increase of 8-60 times in a matter of 4 yr. Lead and cadmium concentrations also increased but at a relatively lower level, about 3-8 times more. The magnitude of pollution in the Sien-San coastal area is clearly demonstrated by the dramatic increase in the oyster copper and zinc concentrations.

In addition to the rapid increase of oyster metal concentrations, surface sediment metal concentrations also showed a concurrent change with the exception of cadmium for those samples collected in 1993 and 1997 (Fig. 4). Similar to the oysters, surface sediment metal concentrations for the 1993 samples varied within a rather limited range $(\mathrm{Cu}: 0.183-2.41 \mathrm{ppm}, \mathrm{Zn}: 17.1-83.2 \mathrm{ppm}$, Pb: 4.85-20.1 ppm, Cd: 0-99.5 ppb, Fe: 0.4-1.18\%), as compared to the copper concentration of the 1997 sediments which increased to as high as 200 ppm, nearly 100fold within a short period of $4 \mathrm{yr}$. $\mathrm{Zn}$ and $\mathrm{Pb}$ increased only slightly, about 2-3 times more than those in 1993. Increases of copper concentrations in the 1997 sediments were astonishing as compared to the 1993 sediments.
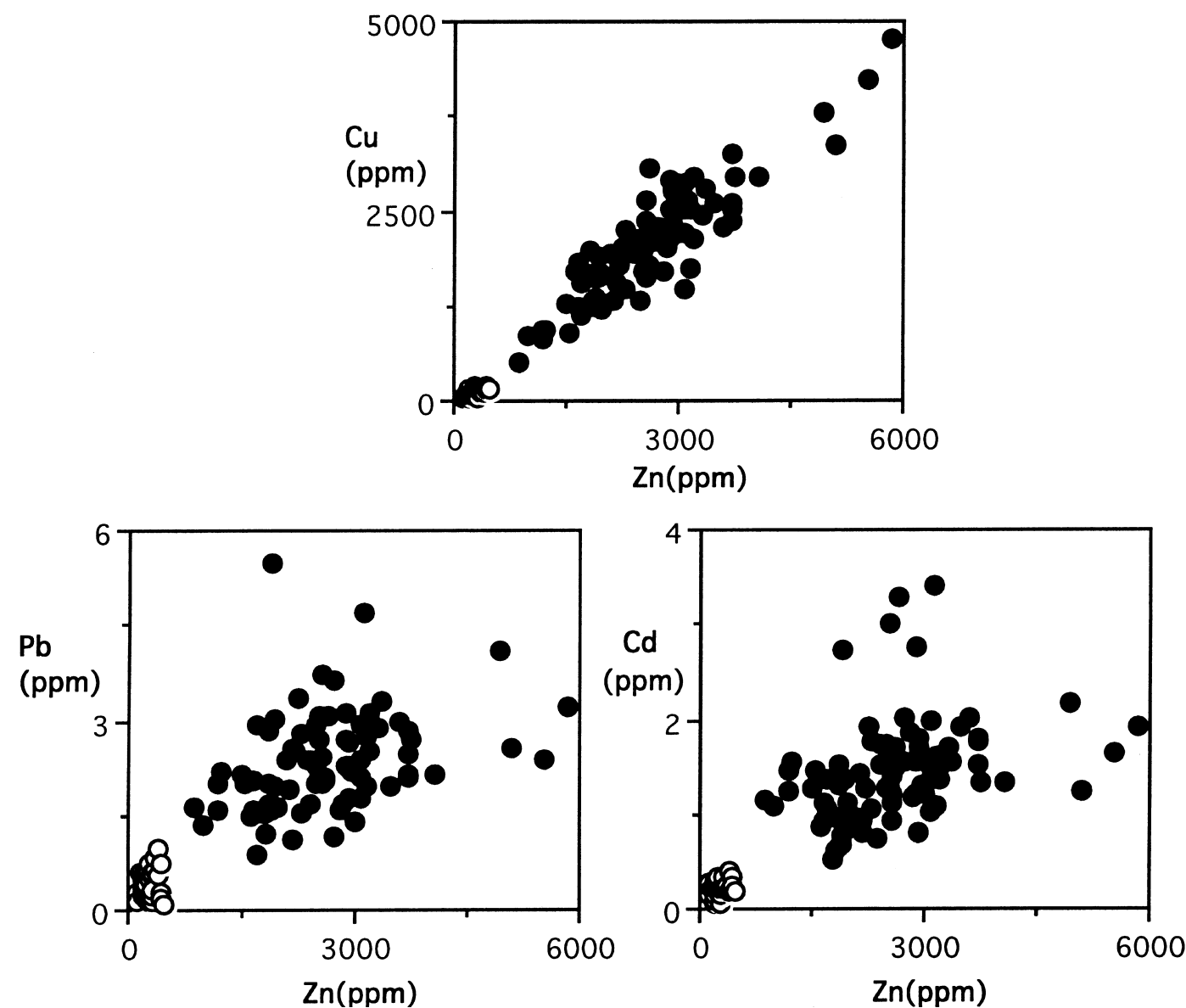

Fig. 3 Concentrations (ppm, dry weight) of $\mathrm{Cu} / \mathrm{Zn}, \mathrm{Pb} / \mathrm{Zn}$ and $\mathrm{Cd} / \mathrm{Zn}$ in whole soft parts of oysters collected in $1997(0)$ and 1993 (O). 

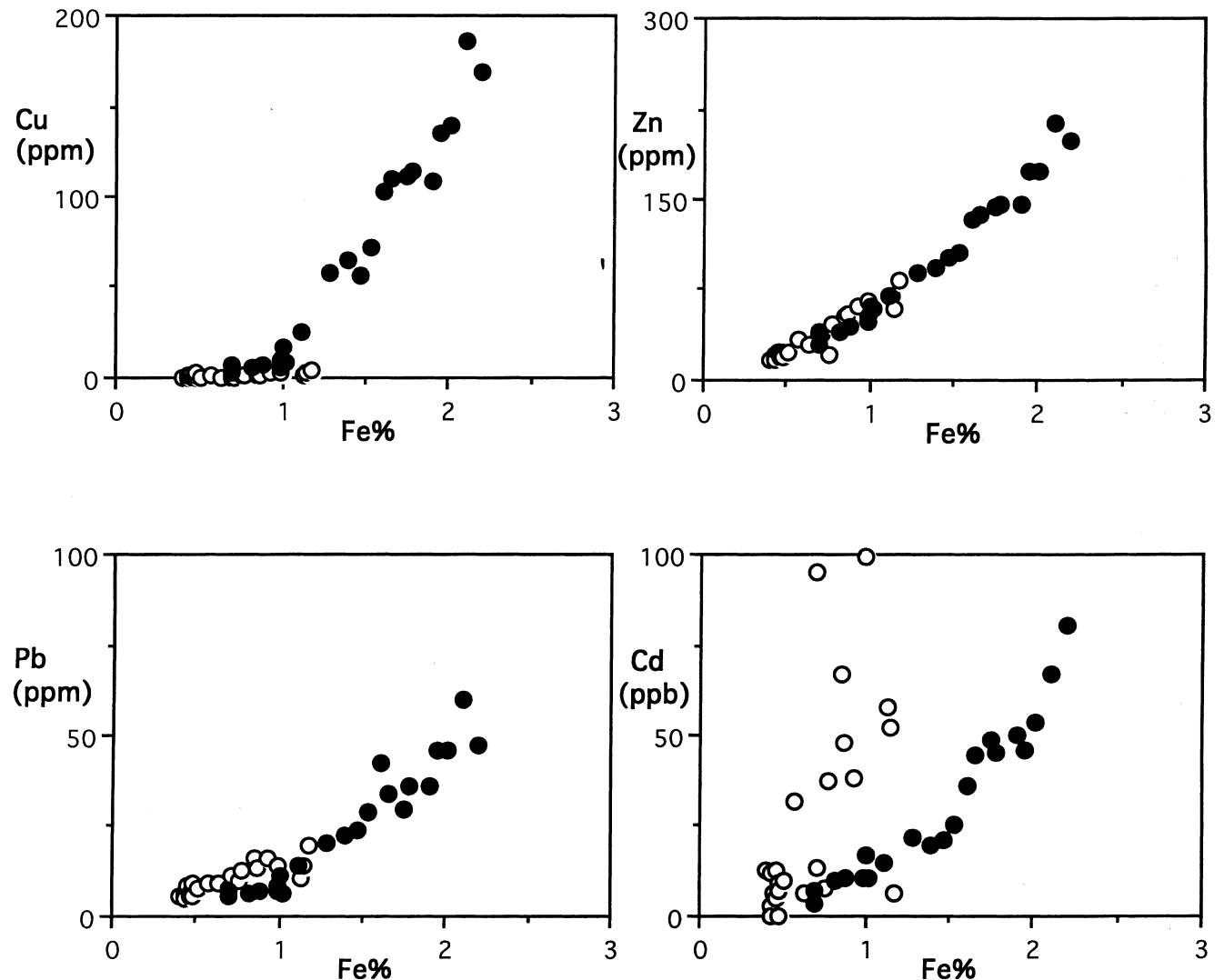

Fig. 4 Concentrations of $\mathrm{Cu}, \mathrm{Pb}$ and $\mathrm{Cd}$ versus $\mathrm{Fe}$ in the sediments collected in 1997 (O) and $1993(\bigcirc)$.

In the Sien-San area, the highest sediment copper concentration was $190 \mathrm{ppm}$. Back in 1986, the highest $\mathrm{Cu}$ concentration found in sediments beneath the oyster was no more than $51 \mathrm{ppm}$ when green oyster occurred in the Er-Jin Chi area, south-western Taiwan due to the huge quantity of effluent from the scrap metal reprocessing industry ( $\mathrm{Su}$ et al., 1986). The average copper concentration of the Sien-San area is $61.0 \pm 54.9 \mathrm{ppm}$ as compared to the $18 \pm 9.1 \mathrm{ppm}$ that was observed in the Er-Jin Chi sediments. Consequently, the extent of copper pollution in the Sien-San area is most likely even worse than the pollution in the Er-Jin Chi area during its peak time.

This extensive pollution may subsequently resulted in a great financial loss to the fishing community. Back in 1986 the year the first green oyster pollution was found, a rapid oyster price drop from US $\$ 3$ to $\$ 1.50$ per kilogram and a sharp oyster production decline from 29000 to 21000 tons was observed within $2 \mathrm{yr}$ right after the incident (Chien, 1992). The decline in oyster production was not a direct result of the detrimental effect of the scrap metal pollution; rather it was a reaction to the market as the oyster retail price dropped rapidly. The total loss as a result of the 1986 green oyster pollution amounts to approximately US\$70 million, representing $50 \%$ of the entire oyster business in Taiwan (Chien, 1992). The impact that this green oyster incident will have on the oyster business is not clear since the statistic of the 1997 oyster production has not been released yet. The recurrence of the green oysters indicated that the Sien-San coastal environment is being polluted as a result of the rapid development of a computer-related industry in the region. This pollution problem represents a serious threat to the local fishing community.

\section{Conclusion}

The Sien-San coastal area of north-west Taiwan is undergoing rapid change from urban development and computer-related industries. Contamination of the coastal area by toxic residues such as copper is reflected in the extreme high levels of metals found in the oysters and sediments.

Copper concentrations in the sediments and oyster reached as much as 200 and $5000 \mathrm{ppm}$, respectively. The green oyster phenomenon occurred as a result of these rapid increases of metal concentrations. In addition, the accordant rapid increase of copper concentrations in the sediment and oyster within a short period of only $4 \mathrm{yr}$ demonstrates that the Sien-San coastal area is under the drastic stress of copper pollution. This pollution problem represents a serious threat to the local fishing community.

The author thank the suggestions from the reviewer which greatly improved this paper. We also wish to thank Fu-Lian Lin and PingShien Huang for their help in sampling. This study was partially 
supported by the Council of Agriculture, COA-87-AST-1.10-FID04(4).

Ayling, G. M. (1974) Uptake of cadmium, zinc, copper, lead and chromium in the Pacific Oyster, Crassostrea gigas, grown in the Tamar River, Tasmania. Water Research 8, 729-838.

Chien, Y. H. (1992) Aquaculture in the Republic of China: a biosocioeconomic analysis of the aquaculture industry in Taiwan. In Aquaculture in Asia, eds. I. C. Liao, C. Z. Shyu and N. H. Chao, pp. 31-50. Proceedings of the 1990 APO Symposium on Aquaculture.

Fisheries Bureau (1997) Fisheries yearbook, Taiwan Area, 1996. Taiwan Fisheries Bureau, Department of Agriculture and Forestry, Provincial Government of Taiwan, p. 379

George, S. G., Pirie, B. J. S., Cheyne, A. R., Coombs, T. L. and Grant, P. T. (1978) Detoxification of metals by marine bivalves: an ultrastructural study of the compartmentation of copper and zinc in the oyster Ostrea edulis. Marine Biology 45, 147-156.

Goldberg, E. D., Koide, M., Hodge, V., Flegal, A. R. and Martin, J. (1983) US Mussel Watch: 1977-1978 Results on trace metals and radionuclides. Estuarine Coastal and Shelf Science 16, 69-93.

Kokto, S., King, G., Keller, H. R. and Massart, D. L. (1992) Application of chemometrics for the selection of microwave digestion procedures. Analytica Chimica Acta 268, 81-94.

Lankester, E. R. (1886) On green oysters. Quarterly Journal of Microscopic Science 26, 71-94.
Lauenstein, G. G., Robertson, A. and O'Connor, T. P. (1990) Comparison of trace metal data in mussels and oysters from a Mussel Watch Program of the 1970s with those from a 1980 s program. Marine Pollution Bulletin 21, 440-447.

NOAA. (1989) National Status and Trends and Program for Marine Environmental Quality Progress Report: A summary of data on tissue contamination from the first three years (1986-1988) of the Mussel Watch Project. National Oceanic and Atmospheric Administration. Tech. Memo. NOS OMA 49, NOAA/NOS/Coastal and Estuarine Assessment Branch, Rockville, MD, p. 122.

O'Connor, T. P. (1996) Trends in chemical concentrations in mussels and oysters collected along the US coast from 1986 to 1993. Marine Environmental Research 41, 183-200.

Phillips, D. J. H., Ho, C. T. and Ng, L. H. (1979) The rock oyster Saccostrea glomerata as an indicator of trace metals in Hong Kong. Marine Biology 53, 353-360.

Presley, B. J., Taylor, R. J. and Boothe, P. N. (1990) Trace metals in Gulf of Mexico oysters. Science of the Total Environment 97, 551593.

Pridmore, R. D., Roper, D. S. and Hewitt, J. E. (1990) Variation in composition and condition of the Pacific Oyster, Crassostrea gigas, along a pollution gradient in Manukau Harbor, New Zealand. Marine Environmental Research 30, 163-177.

Su, J.-C., Hung, T.-C. and Chen, J.-C. (1986) Ecological and environmental studies along the Er-jin Chi river estuary and coastal area. SCOPE/ROC, Academia Sinica 43, 35. 